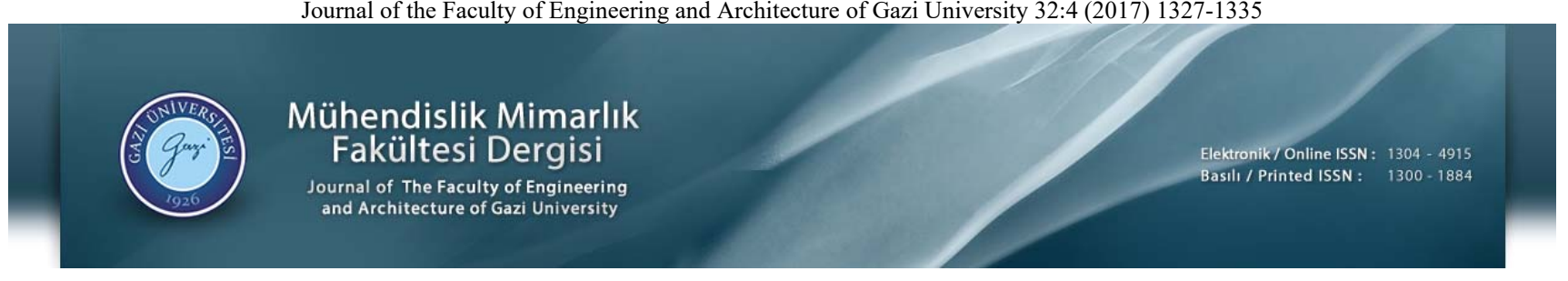

\title{
Sıcak izostatik preslemenin A356 alaşımının metalürjik ve mekanik özelliklerine etkisi
}

\author{
Uğur Aybarç*(D), Ali Kara (D), Halil Emre Çubuklusu(D), Ömer Burak Çe (D) \\ CMS Jant ve Makina San. A.S.., 35620, İzmir, Türkiye
}

\section{Ö N E Ç I K A N L A R}

- Sıcak İzostatik Preslemenin döküm kusurları üzerindeki etkisi

- Sıcak İzostatik Preslemenin döküm Al alaşımlarının mekanik özelliklerine etkisi

- Sıcak İzostatik Presleme ve ısıl işlem uygulanan döküm $\mathrm{Al}$ alaşımlarının özellikleri

Makale Bilgileri

Geliş: 23.08.2016

Kabul: 23.01.2017

DOI:

10.17341/gazimmfd.369853

Anahtar Kelimeler:

Sicak izostatik presleme,

A356,

mekanik ve metalürjik

özellikler,

1sıl işlem
ÖZET

Döküm yöntemi kullanılarak üretilen ürünlerin içyapısında gaz boşluğu ve çekinti meydana gelmesi sıkça karşılaşılan döküm kusurları arasında yer almaktadır. Söz konusu gaz boşluğu ve çekintiler ürünün mekanik özelliklerini olumsuz yönde etkileyerek faydalı kullanım ömrünü azaltmaktadır. Bu durum özellikle alüminyum ve alüminyum alaşımlarını kullanarak ürün üreten firmalar için büyük bir önem taşımaktadır. $\mathrm{Bu}$ kusurların giderilmesi için farklı teknikler kullanılarak gerçekleştirilen gaz giderme işlemleri ve üretim proses optimizasyon çalışmaları yaygın bir şekilde yapılmaktadır. Bu çalışmada mevcut durumlarda kullanılan iyileştirme uygulamalarına alternatif takipçi işlem adımı olarak Sıcak İzostatik Pres uygulaması denemelerine ait detaylar yer almaktadır. Çalışma kapsamında A356 alaşımı kullanılarak açık atmosfer döküm ile elde edilen numunelere üretim aşamalarının farklı noktalarında HIP prosesi uygulanmıştır. Uygulama sonrası numunelerin mekanik ve metalürjik özelliklerinde meydana gelen değişiklikler incelenerek elde edilen bulgular ortaya konmuştur.

\section{Effect of hot isostatic pressing on metallurgical and mechanical properties of A356 alloy}

\section{H I G H L I G H T S}

- The effects of Hot Isostatic Pressing on casting defects

- The effect of Hot Isostatic Pressing on mechanical properties of casting Al alloys

- $\quad$ Properties of cast $\mathrm{Al}$ alloys treated with Hot Isostatic Pressing and heat treatment

\section{Article Info}

Received: 23.08.2016

Accepted: 23.01.2017

DOI:

10.17341/gazimmfd.369853

Keywords:

Hot isostatic pressing,

A356,

mechanical and metallurgical

properties,

heat treatment.

\section{ABSTRACT}

Shrinkage and porosity are the common defects of the cast products. These defects affect mechanical properties of cast product negatively and decrease the useful life of the product. Solving these defects is quite important for companies manufacturing parts from Aluminum and its alloys. In order to eliminate these defects, various degassing techniques and manufacturing process optimization practices are generally performed in practice. In this study, the details of Hot Isostatic Pressing (HIP) applications were presented as an alternative follower process to current practice. In the scope of the study, HIP was applied at various steps of the specimens made of A356 alloy and by open atmosphere casting method. The results of effect of HIP on mechanical and metallurgical properties of specimens were presented in the study.

\footnotetext{
*Sorumlu Yazar/Corresponding Author: uaybarc@cms.com.tr / Tel: +90 2323991100 / 5920
} 


\section{GİRIŞ̧ (INTRODUCTION)}

Günümüzde özellikle otomotiv ve havac1lık endüstrilerinde meydana gelen gelişmeler, yüksek mekanik özelliklere sahip hafif ürünlerin geliştirilmesini gerektirmektedir [1, 2]. Bu gereksinim, farklı döküm yöntemleriyle [3, 4], kolaylıkla dökülebilmesi ve döküm özelliklerinin iyi olmasının [5] yanı sıra mekanik özelliklerinin çeşitli metalürjik işlemler ile geliştirilebilmesi ve iyi bir korozyona dayanım özelliğine sahip olması alüminyumun önem kazanmasına yol açmaktadır [6, 7]. Ancak alüminyum alaşımlarında katılaşma süresince porozite oluşumu, mekanik açıdan başta gelen içyapı kusurlarındandır ve nihai ürünün mekanik özelliklerine olumsuz yönde etki etmektedir [8]. Oluşan porozite, malzemenin mukavemetini azaltır ve gevrekleşmesini yani \%uzamasının azalmasını sağlar. Döküm yöntemiyle üretilen ürünler farklı mikro-yapılara sahip olup hacimsel hatalar (porozite, çekinti boşlukları gibi) içerebildiklerinden dolayı değişken mekanik özellikler göstermektedir. Porozite, alüminyum alaşımlarının dökümünde en önemli hatalardan biri olarak kabul edilmektedir ve yapı içerisinde porozitenin yer alması, dökümün mekanik özelliklerini ve korozyon dayanımını olumsuz yönde etkilemektedir. Dökümde porozitenin oluşumu katılaşma sırasında gazın çözeltide çökelmesi ya da hacimsel çekintileri telafi etmek için sıvı metalin taneler arası bölgeleri beslemesindeki yetersizliklerinden kaynaklanmaktadır [9]. Yapı içerisindeki porozitelerin giderilmesi istenilen mekanik özelliklerin (mukavemet, tokluk, \%uzama gibi) elde edilmesinde son derece büyük bir öneme sahiptir [10].

Sicak İzostatik Pres (Hot Isostatic Press-HIP) yöntemi; çekinti boşlukları, mikroporlar, sıcak yırtılma gibi porozite kusurlarını ortadan kaldırabilmektedir [11, 12]. HIP, metallerdeki porozite, çekinti gibi döküm hatalarını azaltmak ve seramik malzemelerde yoğunluğu arttırmak üzere geliştirilmiş bir yöntemdir [13]. HIP uygulanacak komponent, yüksek basınca dayanıklı bir tankın içerisine konur, çok yüksek basınç altında 1sıtılmış bir gaz kullanılarak işlem gerçekleştirilir [14]. Basınçlandırmada genellikle Argon kullanılmakla birlikte, diğer asal gazlar da kullanılabilmektedir. Basıncın arttırılması dolayısıyla komponentin her yönünden eşit miktarda yükleme olması sonucu izostatik yükleme gerçekleştirilmiş olur. Literatürde HIP işleminin döküm kusurlarını gidermede ve mekanik özelliklere etkisi ile ilgili farklı alaşımlar üzerinde gerçekleştirilmiş çalışmalar mevcuttur. Lee vd. [15] HIP işleminin hassas dökümle üretilmiş A356 alaşımının yüksek çevrimli yorulma özelliklerine etkisini incelemişlerdir. Çalışmalarında yorulma mukavemetinde \%40-50 civarında bir artış elde etmişlerdir. $\mathrm{Bu}$ sonucu döküm içerisindeki mikroporların hacimsel oranının azalması ile açıklamışlardır. Ceschini vd. [16] kuma döküm yöntemiyle üretilmiş A356 ve A204 alaşımından numuneler üzerinde gerçekleştirdikleri yorulma araştırmalarında, malzemelerin yorulma mukavemetlerinde gözlemledikleri yüksek miktarda artış (A356 için \%40, A2O2 için \%70 seviyesinde) yanında, test sonuçlarının sapmasındanki azalmayı da raporlamışlardır. Ran vd. [17] çalışmalarında modifiye edilmemiş, kuma döküm A356-T6 alaşımının mikro yapısını (TEM, SEM, optik mikroskop, fraktografi) ve mekanik özelliklerini incelemişlerdir. Bu çalışmada da mekanik özelliklerdeki dağılımın azaldığı ve incelenen tüm ikincil dendirit kol mesafeleri aralığ için çekme mukavemetinin ve uzamanın arttığı raporlanmıştır. HIP prosesinin (taneler arası) kırılma modunu değiştirmediği de belirtilmiştir. Staley Jr. vd. [18] ötektik ergime sıcaklığına kadar yükseltilen HIP sıcaklıklarının A206-T71 alaşımının bifilm ve çekme özelliklerine etkisini incelemişlerdir. Uzama miktarında oldukça yüksek artış (ortalama \%1.4'ten ortalama \%18'e) gözlemlenmiş, ancak sıcaklığın artışının HIP etkisini çok değiştirmediği gözlemlenmiştir ve bunu kalın spinel bifilm oluşumuna bağlamışlardır. Dedyaeva [19] vd. Al-10Si alaşımının mikroyapısına ve özelliklerine HIP işleminin etkisini incelemişlerdir. Sonuçlar, alaşımın HIP prosesi sonucunda, termal genleşme katsayısının ve mikrosertiliğinin azaldığını göstermiştir. Homojenliği artan alaşımda düşük porozite ile birlikte optimuma yakın bir içyapıya sahip olduğunu bildirmişlerdir. A356 alaşımı diğer kullanım yerlerinin yanında alüminyum alaşımlı araç jantı üretiminde günümüzde en çok kullanılan alüminyum alaşımıdır [20]. Alçak basınçlı döküm yöntemi ise bu alaşımla jant üretiminin ana proses adımıdır. $\mathrm{Bu}$ yöntemle üretilen jantlar takip eden isıl işlem ve görece yüksek sıcaklıklarda (yapay yaşlanmaya sebep olabilir) boya kurutma prosesine maruz birakılabilmektedir [21]. Bu sebeple bu çalışmanın amacı jant üretiminde kullanılan A356 alaşımının HIP ve ısıl işlem ile boya prosesi kaynaklı yapay yaşlandırma kombine etkileri altındaki mekanik özelliklerinin incelenmesidir. Proses kapsamında janttan numune alınmayıp açık atmosfer döküm ile standart numuneler dökülerek geometriden bağımsız inceleme gerçekleştirilmiştir. Çalışma sonucunda mekanik özellikler üzerinde HIP ve takipçi işlem adımlarının etkilerinin birbirlerini destekleyici ya da azaltıcı şekilde olabildiği (farklı parametrelerde farklı sonuçlar gözlenmiştir) gözlemlenmiştir.

\section{DENEYSEL METOD (EXPERIMENTAL METHOD)}

Bu çalışmada A356 alaşımının mekanik özelliklerine HIP işleminin etkisi jant üretiminde uygulanan döküme takipçi işlem adımlarıyla kombine olacak şekilde incelenerek jant üretim prosesinde uygulanması halinde proses geliştirme çalışması gerçekleştirilmiştir. Dolayısıyla bu çalışmanın uygulama kısmında numunelerin üretilmesi için jant üretiminde kullanılan A356 alüminyum alaşımı esas alınmıştır. Tablo 1'de A356 alaşımının kimyasal kompozisyonu verilmiştir. Deneylerde kullanılmak üzere oluşturulan numune üretimi süreç adımları Şekil 1'de gösterilmektedir. Şekil 1'deki numune üretim sürecine göre dökümler gaz giderme işlemi uygulanmış ve uygulanmamış olarak iki ayrı grupta da gerçekleştirilmiştir. Bunun sonucunda gaz giderme etkinliği ve ayrıca gaz giderme gerçekleştirilmemiş alaşımın HIP sonrası mekanik 
Tablo 1. A356 alaşımının kimyasal kompozisyonu (Chemical composition of A356 alloy).

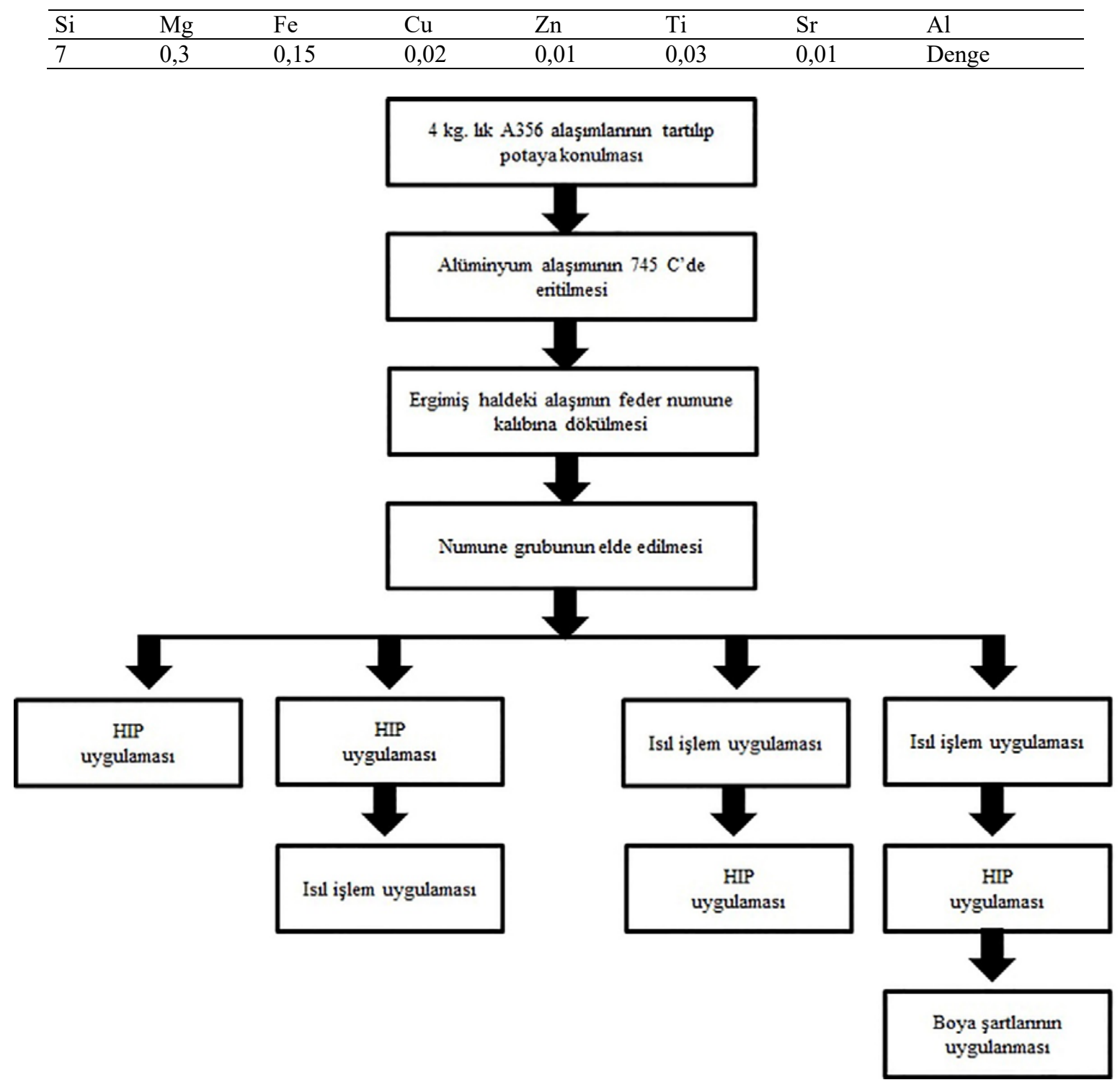

Şekil 1. Numune üretim süreci (Specimen preparation process)

performansı da incelenebilmiştir. Döküm işlemleri laboratuvar ortamında $745^{\circ} \mathrm{C}$ 'de ergitilmiş alaşım külçeden hazırlanmış olup dökümün yapıldığ 1 kalıp ve numune grubu Şekil 2'de gösterildiği gibidir. Döküm işleminden önce üretilen numunelerin kalıba yapışmaması ve kalıptan kolay ayrılması amacıyla kalıp iç yüzeyine seramik esaslı bir kaplama işlemi uygulanmıştır. Jant üretim sürecindeki termal çevrimin doğru temsili ve standart numuneler elde edilebilmesi amacıyla her numune dökümünden önce kalıp $320^{\circ} \mathrm{C}$ 'ye 1 sıtılmış ve ardından döküm işlemi gerçekleştirilmiştir.

Kalıp içerisinde katılaşan numune grubu ardından su verme havuzunda soğutulmuştur. Üretilen numunelerin 1 sıl işlem uygulanacak olanlarına 4 saat $540^{\circ} \mathrm{C}$ 'de çözeltiye alma, su verme ve 4 saat $150^{\circ} \mathrm{C}^{\prime}$ de yaşlandırma işlemini içeren $\mathrm{T} 6$ 1sıl işlem uygulaması yapılmıştır. Daha önce de bahsedildiği gibi 1sıl işlem uygulamasından sonra jantlar talaşlı imalat ve boya proseslerine maruz kalmaktadır. Bu boya prosesindeki yüksek sıcaklıklar T6 isıl işleminden sonra ekstra bir yaşlandırmaya sebebiyet verebilir. Bu etkinin de göz önünde bulundurulması ve jant üretim prosesinde kullanılması halinde prosesin hangi aşamasında uygulanması gerektiğinin tespiti amaciyla boya prosesi de bir parametre olarak belirlenmiş ve çalışma kapsamında değerlendirilmiştir. HIP işleminin uygulanması için Dokuz Eylül Üniversitesi Elektronik Malzemeler Uygulama Merkezi (EMUM)'nde kurulu bulunan American Isostatic Presses firmasının AIP6$30 \mathrm{H}$ cihazı kullanılmıştır (Şekil 3). Bu cihaz Ar, N ve Ar20\%O gazları ile çalışabilmektedir. $207 \mathrm{MPa}$ maksimum basınç uygulayabilmektedir. $1200-2200^{\circ} \mathrm{C}$ sicaklığa kadar 1sıtma kapasiteli akuple firınlar ile kullanılabilir. 


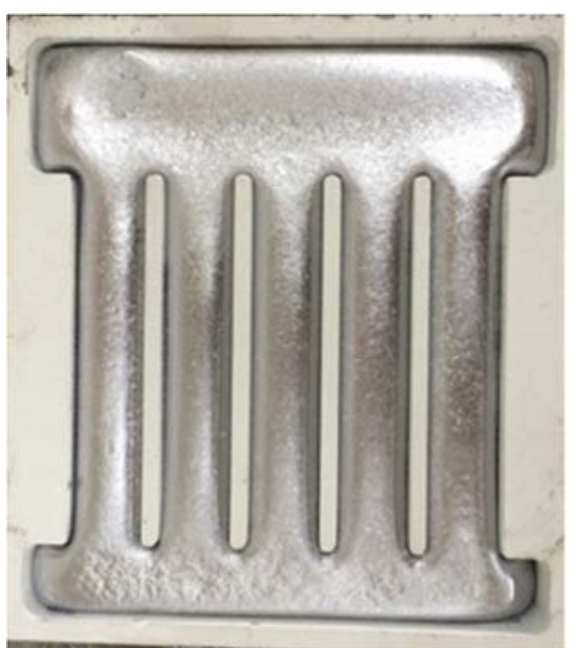

(a)

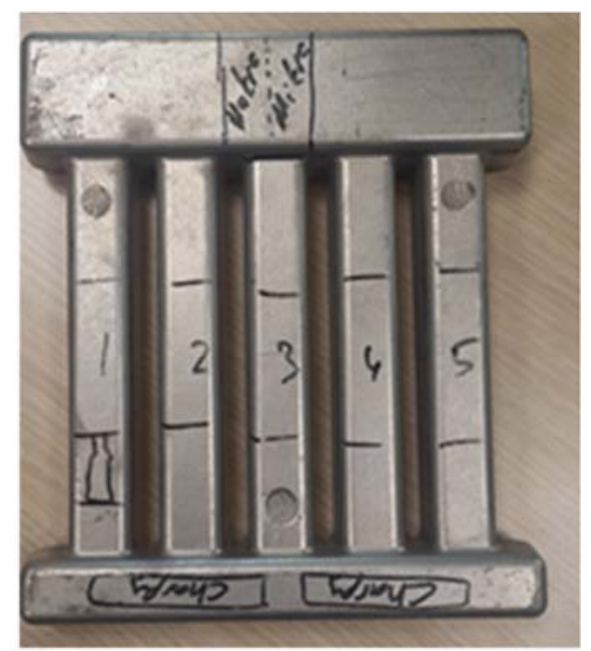

(b)

Şekil 2. a) Numune Döküm Kalıbı b) Üretilen Numune Grubu (a) Specimen casting mould b) Cast specimens)



Şekil 3. EMUM Sicak İzostatik Presleme cihazı (Hot Isostatic Pressing device)

$\mathrm{Bu}$ çalışmada HIP proses şartları, literatürde yapılan çalışmalarda belirtilen parametreler göz önünde bulundurularak belirlenmiştir. Prosesin bir katı hal prosesi olması dolayısıyla solidus sıcaklığının altında kalmasına ancak işlem sonucu beklenen iyileştirmeleri sağlayacak en yüksek sıcaklığa ulaşmasına çalışılmıştır. Literatürde solidus-likidus arası sıcaklıklarda gerçekleştirilen uygulamalarda porozitede iyileşme yerine artış gözlemlendiği de raporlanmıştır [19]. Buna göre, HIP işlemi için parametreler aşağıdaki gibi belirlenip HIP içeren tüm numunelere buna göre uygulanmıştır.

- S1caklık: $510^{\circ} \mathrm{C}$

- Basınç: $100 \mathrm{MPa}$

- Uygulama süresi: 2 saat

- Soğutma işlemi: $50^{\circ} \mathrm{C} / \mathrm{dk}$

1330
Şekil 2(b)'de görülen dökülmüş alüminyum numune grubundan her deney parametresi için iki numune çıkarılmıştır. Numuneler HIP'de kullanılacak hazne boyutu kısıtlı olduğu için Şekil 4'teki gibi iki grup olarak uygulamaya alınmış ve her parametre için elde edilen 2'şer numune farklı uygulama grupları ile cihaza konulmuştur. Elde edilen silindirik numuneler talaşlı imalat prosesinden önce HIP işlemine tabi tutulmuştur. HIP cihazının haznesine sığabilecek toplam boyutta ve sayıdaki numune tel ile sarılmış ve Şekil 4'te gösterildiği gibi işleme sokulmuştur.

HIP prosesinde uygulanan basınç ve sıcaklığın zamana bağlı değişimi Şekil 5'teki gibidir. Görüldüğü gibi sıcaklık ve basınç lineer olarak istenilen değere arttırıldıktan sonra istenen süre kadar bu sıcaklık ve basınçta beklenerek proses gerçekleştirilir. İstenen sürenin geçmesi sonucunda (bu 


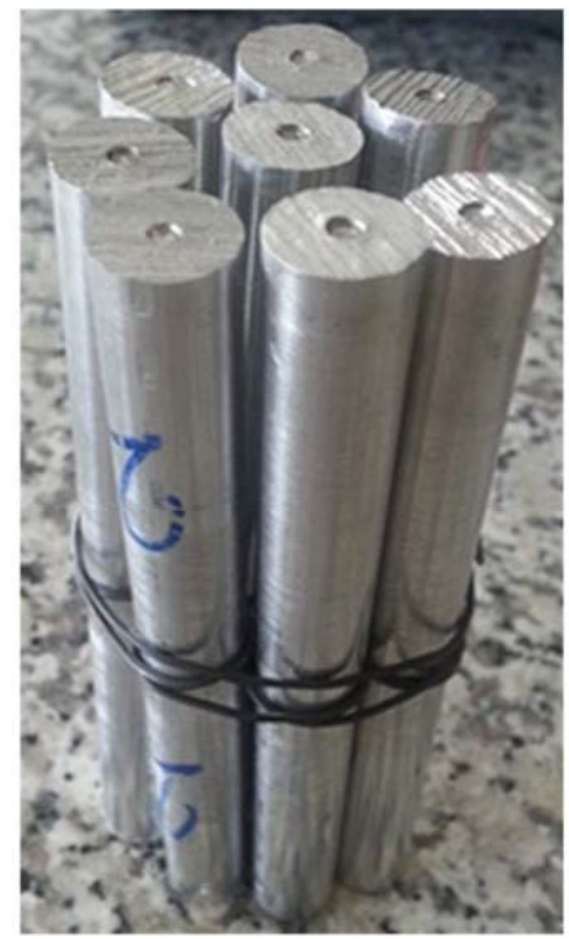

(a)

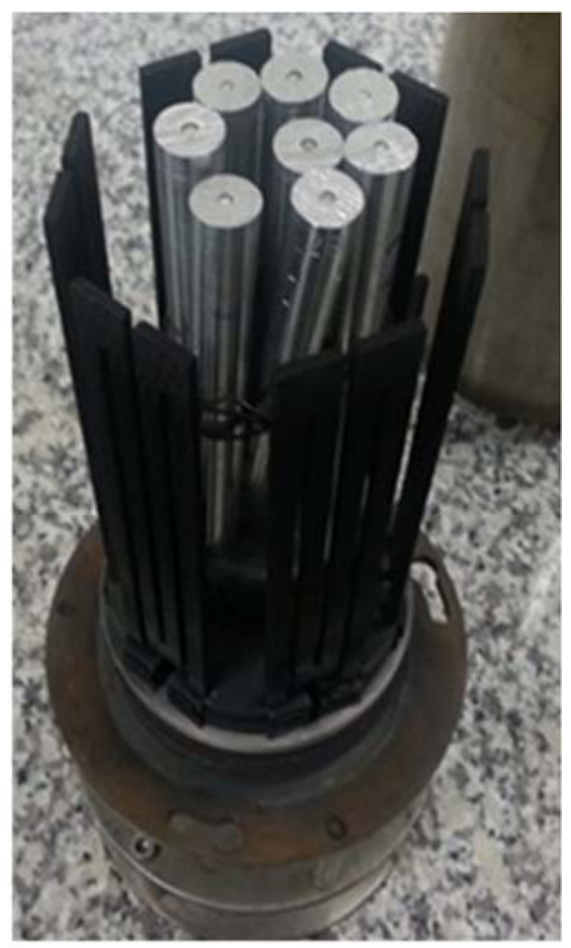

(b)

Şekil 4. a) Numunelerin Gruplandırılması b) Numunelerin HIP'in haznesine yerleştirilmesi. (a) Grouping specimens b) Placement of specimens in HIP chamber)

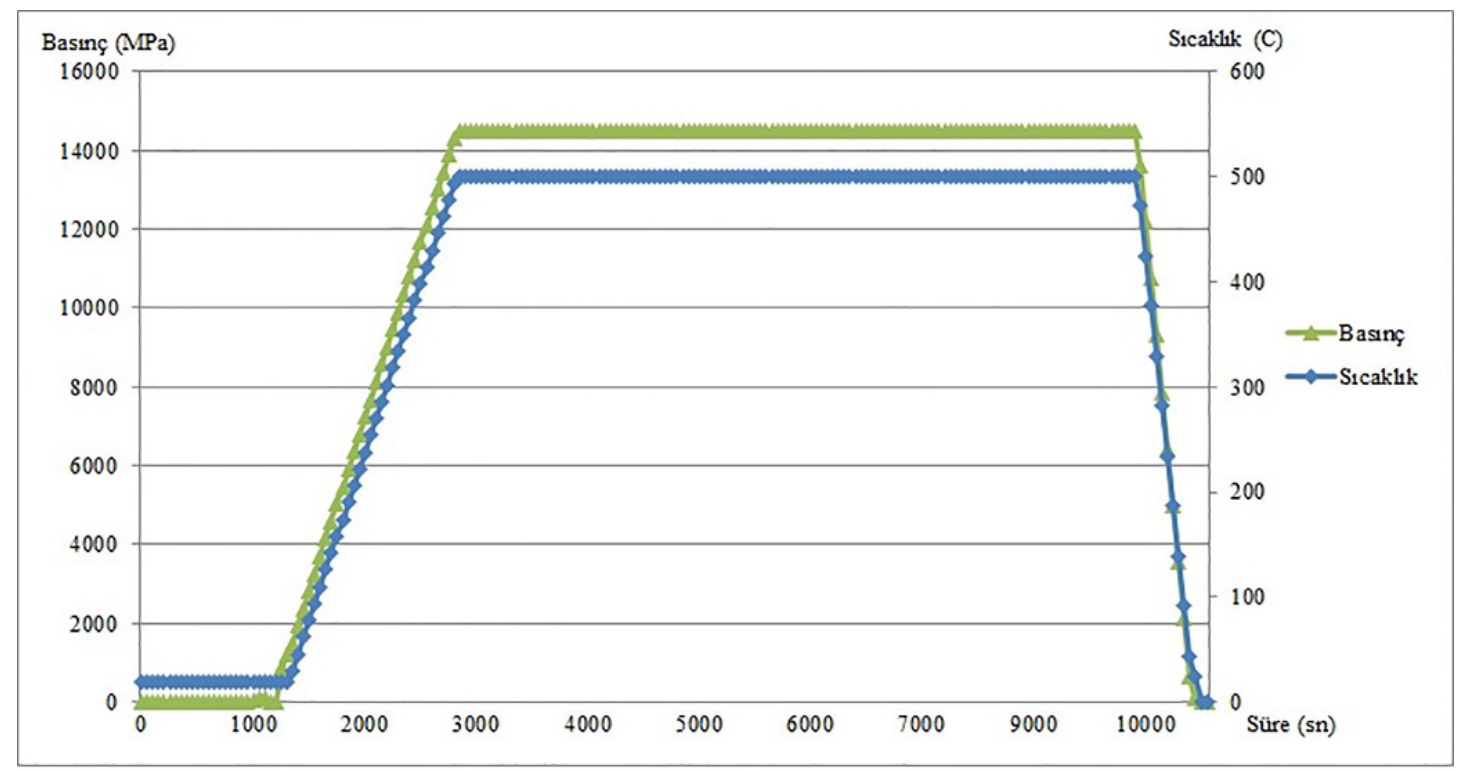

Şekil 5. Sicak İzostatik Presleme (HIP) proses parametreleri (Hot Isostatic Pressing process parameters)

çalışmada 2 saat) belirlenen soğutma hızında numune soğutulup oda sıcaklığına getirilir. Bu işlemin tamamlanması ile elde edilen numuneler 1sıl işlem uygulanacaksa 1sıl işlem prosesine, yoksa talaşlı imalat prosesine alınır ve uygun boyutta çekme numuneleri hazırlanır. Tüm numunelerin boyutları ve deney şartları DIN EN ISO 6892-1 standardında belirtildiği gibidir. Çalışma kapsamında üretilen numuneler üzerinde çekme testleri 100 kN kapasiteli vidalı Zwick Z100 malzeme test cihazında gerçekleştirilmiştir. Temaslı ekstensometrelerin kullanımı ile direkt olarak numune şekil değiştirmesi tespit edilmiş ve cihazın elastik deformasyonları elimine edilmiştir. Çalışma kapsamında içyapı incelemeleri de gerçekleştirilmiş olup, bu incelemelerde Nikon EPIPHOT 200 optik mikroskop kullanılmıştır. Tablo 2'de Şekil 1'e paralel olarak deneyleri gerçekleştirilen numune matrisi görülebilir. 
Tablo 2. Deney listesi (Ĕ̆er mevcutsa işlem sırasına göre numaralandırılmıştır) (Experiment list (Numbered according to process sequence if the process exist))

\begin{tabular}{lllll}
\hline \multirow{2}{*}{ Numune No } & $\begin{array}{l}\text { Gaz } \\
\text { Giderme }\end{array}$ & $\begin{array}{l}\text { Iss1 } \\
\text { İşlem }\end{array}$ & $\begin{array}{l}\text { Boya } \\
\text { Şart1 }\end{array}$ & HIP \\
\hline 1 & - & - & - & 1 \\
2 & 1 & - & - & 2 \\
3 & - & 2 & - & 1 \\
4 & 1 & 3 & - & 2 \\
5 & - & 1 & - & 2 \\
6 & 1 & 2 & - & 3 \\
7 & - & 1 & 3 & 2 \\
8 & 1 & 2 & 4 & 3 \\
\hline
\end{tabular}

\section{SONUÇLAR VE TARTIŞMALAR (RESULTS AND DISCUSSIONS)}

Şekil 6'da HIP işlemi uygulanmış numunelerin yüzeyinden görüntüler verilmiştir. Görülebileceği gibi uygulanan basıncın etkisi ile malzeme içerisindeki porozitelerin çöktügü ve kapandığı ve dolayısıyla yüzeyde çöküntü şeklinde görüntüler gözlemlendiği açıktır.

Çekme testlerine ait sonuçlar Şekil 7'de verilmektedir. Şekil 7 göz önüne alındığında her sonucu ayrı ayrı değerlendirmek gerekirse;

Akma değerlerine göre; döküm sonrası uygulanan HIP, hem gaz giderme uygulanmamış hem de uygulanmış numuneler için birbirine oldukça yakın sonuçlar göstermektedir. Buna karşılık HIP işlemi sonrası uygulanacak bir ısıl işlem sonrası akma dayanımlarının yaklaşık üç katına çıktığı görülmektedir. Bunun ana nedeni HIP işlemi ile birlikte yapı içerisindeki porların giderilmesi işlemi [15] ve A356 alüminyum alaşımına ısıl işlem uygulanması durumunda yapı içerisinde mukavemet artışını sağlayan $\mathrm{Mg}_{2} \mathrm{Si}$ fazlarının oluşması şeklinde yorumlanabilir. Diğer numune gruplarına bakıldığında 1sıl işlem sonrası HIP ve 1sıl işlem sonrası HIP ve Boya şartlarının uygulanması HIP'in uygulama mantığ gereği çıkılan sıcaklıkta yap1 içerisinde oluşan $\mathrm{Mg}_{2} \mathrm{Si}$ fazlarının etkinliğini azaltarak malzemenin mekanik özelliklerini kötü yönde etkilediği görülmektedir [17].

Kopma değerlerine göre; akma değerleri de paralel sonuçlar göstermektedir. Burada döküm sonrası uygulanan HIP hem gaz giderme uygulanmamış hem de uygulanmış numuneler için birbirine oldukça yakın sonuçlar göstermektedir. HIP sonrası 1sıl işlem uygulanması durumunda kopma dayanımı yaklaşık 1,8 oranında artmaktadır. Isıl işlem sonrası uygulanacak HIP ve HIP sonrasi uygulanacak Boya uygulama şartları sonrasında kopma dayanımlarını tekrar düşmektedir. Değerlerde gözlemlenen düşmenin akma dayanım değerlerinde ifade edilen nedenle aynı olduğu söylenebilir.

\% uzama değerlerine göre; döküm sonrası uygulanan HIP ile gaz giderme işlemi uygulanmış numune gaz giderme uygulanmamış numunenin 1,5 katı \% uzama gösterdiği görülmektedir. Buna karşılık akma ve kopma dayanımlarının en yüksek olduğu HIP sonrası 1sıl işlem uygulaması yapılan numunelerin \% uzama değerleri diğer numunelerin 1/3' kadardır. Bunun nedeni mukavemetin yüksek olması nedeniyle numunede boyun verme olayı gerçekleşmeden kırılma meydana gelmesi olduğu söylenebilir. Isıl işlem sonrası HIP uygulamasının yapıldığı numuneler ise en yüksek \%'de uzama değerlerini gösterirken HIP sonrası boya uygulama şartlarına maruz bırakılan numunelerin \%'de uzama değerleri \%11'in üzerinde elde edilmiştir. Lee vd. [15] yapmış olduğu çalışmada gaz giderme işlemi uygulanmış ve uygulanmamış numunelere HIP işleminin uygulanmasının ardından benzer şekilde akma ve çekme mukavemetlerinde artış elde etmişler ve bu sonucun HIP işlemi sayesinde numunelerdeki porozitelerin azaltılması nedeniyle elde edildiğini ifade etmişlerdir. Tüm bu sonuçlar göz önüne alındığında, \%uzama değerlerinin kabul edilebilir olduğu varsayımıyla, mekanik anlamda en uygun prosesin döküm ardından HIP ve akabinde 1sıl işlem uygulaması olduğu görülmüştür.

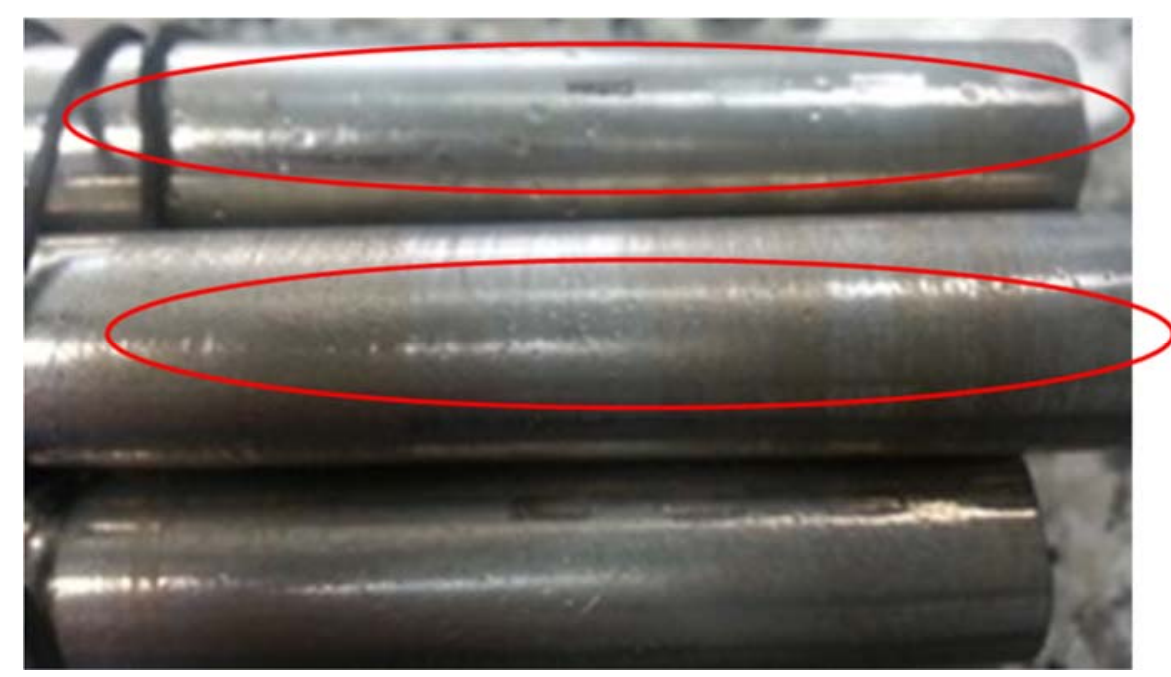

Şekil 6. Sıcak İzostatik Presleme uygulanmış numunelerin yüzeyinden bir görüntü (A view from Hot Isostatic Pressing applied specimens) 



Şekil 7. Numune çekme test sonuçları a) Akma dayanımı b) Kopma dayanımı c) \% uzama (Specimen tensile test results a) Yield strength (b) Tensile strength (c) \%elongation) 
Jant üretiminde boya prosesinin zorunlu olması dolayısıyla proseste boyayı da dahil edecek şekilde güncelleme yapılabilir. Tüm bu sonuçlardan ayrıca görülebileceği gibi gaz giderme prosesinden en çok etkilenen parametre ise \%uzama olup diğer mekanik özellikler bundan o kadar etkilenmemektedir. Bu değerler standart A356 ve A356-T6 alaşımları için aşağıda Tablo 3'de verilen değerler ile karşılaştırmalı incelenebilir. Buna göre döküm ve ardından HIP uygulamas1 sonucu elde edilen numune standart alaşımdan daha düşük performans göstermiştir. Döküm HIP ve akabinde isıl işlem uygulanan numune \%uzama özellikleri standart alaşıma yakınken akma mukavemeti ve kopma mukavemeti de isıl işlemli alaşımdan oldukça yüksektir. Bu sonuçlar bu prosesin jant üretiminde de uygulanabilir olduğunu ortaya koymaktadır.

Tablo 3. Tipik gaz gidermesiz A356 ve A356-T6 alaşımlarının mekanik özellikleri

(Typical mechanical properties of non-degassed A356 and A356-T6 alloys)

\begin{tabular}{llll}
\hline Alaşım & $\begin{array}{l}\text { Akma } \\
\text { Mukavemeti } \\
(\mathrm{MPa})\end{array}$ & $\begin{array}{l}\text { Kopma } \\
\text { Mukavemeti } \\
(\mathrm{MPa})\end{array}$ & \%Uzama \\
\hline A356 & 86 & 160 & 6,95 \\
A356-T6 & 200 & 248 & 3,34 \\
\hline
\end{tabular}

Şekil 8'de en uygun mekanik özelliklerin elde edildiği numune olan 3 ve 4 nolu numuneler üzerinde gerçekleştirilen içyapı incelemeleri verilmiştir. İlgili mikroyap1 görüntülerine bakıldığında HIP uygulaması yapılmadan önce yapı içerisinde boşlukların ve porozitelerin olduğu açıkça görülmektedir. Üretim sürecinin farklı noktalarında yapılan bu uygulamaların genelinde HIP uygulaması ile yapı içinde var olan boşluk ve porozitelerin mikroyap1 görüntülerinde de gözle görülür bir şekilde kaybolduğu sonucuna varılmıştır. Özellikle HIP uygulaması sonrasında numunelerin diş yüzeyinde oluşan çukurlaşmalar (Şekil 6) numunenin içyapısındaki bu boşlukların basınç etkisi ile doldurulduğunun bir göstergesi niteliğindedir. Gaz giderme uygulanmış numune incelendiğinde ise aynı işlem uygulanmış numunelere ilave olarak HIP uygulanması yapı içerisindeki porozitelerin bertaraf edilmesinde büyük bir avantaj sağlamaktadır.

\section{SONUÇLAR (CONCLUSIONS)}

Jant üretimi için tokluk en önemli mekanik özelliklerden birisidir. Özellikle bir araçta güvenlik ekipmanı olarak kullanılan jantların kırılmaya uğramadan önce belirli bir deformasyona uğraması gerekmektedir. $\mathrm{Bu}$ duruma göre uygulama kısmında elde edilen sonuçlar birlikte değerlendirilecek olursa, döküm işlemi sonrası uygulanacak HIP ve 1sıl işlem prosesleri jant üretiminde kabul edilebilecek bir tokluk değerlerinin elde edilememesine neden olacaktır. OEM firmalarının belirlemiş olduğu şartnamelere göre akma dayanımlarının minimum $150 \mathrm{MPa}$, kopma dayanımlarının ise minimum $250 \mathrm{MPa}$ olması kabul edilebilir değerlerdir. OEM firmalarının tokluk değerlerini yüksek istemelerinin nedeni jantların kullanımı sırasında hasar olayı öncesi önemli ölçüde plastik deformasyonun meydana gelerek enerji absorblayabilmesidir. Yapılan bu çalışma kapsamında sadece HIP işleminin uygulanması, HIP


Şekil 8. Gaz giderme uygulanmış ve uygulanmamış numunelerin iç yapı incelemeleri sonuçları a) Döküm (GGÖ) b)

Döküm + HIP + Isıl İşlem (GGÖ) c) Döküm (GGS) d) Döküm + HIP + Isıl İşlem (GGS)

(Degassed and non-degassed specimen microstructural observations a) Cast (Non-degassed) b) Cast + HIP + Heat Treatment c) Cast (Degassed) d) Cast + HIP + Heat Treatment (Degassed)) 
işlemi sonrası ilave 1sıl işlem uygulanması, 1sıl işlem sonrası HIP işlemi uygulanması ve 1sıl işlem sonrası HIP işlemi uygulanması ve jant üretimdeki boyama işlemindeki proses şartlarının uygulanması ile dört farklı numune grubu üretilmiştir. Bu numunelerin çekme test sonucu verileri göz önüne alındığında akma değerleri HIP - 70,1, HIP+Isıl işlem-212,2, Isıl işlem+HIP - 73,6 ve Isıl işlem+HIP+Boya$77,8 \mathrm{MPa}$ olarak elde edilmiştir. HIP+Isıl işlem uygulaması dışında elde edilen bu sonuçlar özellikle OEM firmalarının jant üretimi yapan firmalar için belirlediği 150 Mpa olan akma dayanımı değerinin altında olduğu görülmektedir. Benzer şekilde kopma dayanımı da HIP - 153,1, HIP+Isıl işlem-272, Isıl işlem+HIP - 155,4 ve Isıl işlem+HIP+Boya160,7 MPa olarak elde edilmiştir. Bu sonuçların HIP+Isıl işlem uygulaması dışında genel olarak OEM firmalarının belirlediği $250 \mathrm{MPa}$ olan kopma dayanımı değerinin altında olduğu görülmektedir. İzleyen çalışmalarda ifade edilen minimum akma, kopma ve \% uzama değerlerinin elde edilebilmesi için döküm işlemi sonrası uygulanacak HIP ve 1sıl işlem şartlarında değişiklikler yapılarak optimum akmakopma ve \% uzama değerlerine karşılık uygun çalışma parametreleri belirlenebilir. Çalışmanın bulgularından birisi de gaz gidermenin HIP prosesi uygulansa bile \% uzama miktarı üzerinde oldukça fazla etkisinin olduğunu göstermektedir. Bu durum da HIP işleminin işlem sırasından etkilenmektedir.

\section{KAYNAKLAR (REFERENCES)}

1. Timelli G., Camicia G., Ferraro S., Effect of Grain Refinement and Cooling Rate on the Microstructure and Mechanical Properties of Secondary Al-Si-Cu Alloys, J. Mater. Eng. Perform., 23 (2), 611-621, 2014.

2. Büyükuncu M.G., Ötektik Altı Al-Si Döküm Alaşımlarında Bileşimin Optimizasyonu ile Döküm Kabiliyeti ve Mekanik Özelliklerin İyileştirilmesi, Doktora, İstanbul Teknik Üniversitesi, Fen Bilimleri Enstitüsü, İstanbul, 2010.

3. Özcömert M., Otomotiv Endüstrisinde Alüminyum, http://www.ito.org.tr/Dokuman/Sektor/1-68.pdf, Yayın tarihi Aralık 1, 2006. Erişim tarihi Ağustos 2, 2016.

4. Alan S., Alüminyum Raporu, Orta Anadolu İhracatçı Birlikleri Genel Sekreterliği,

http://www.demirbirlik.org/Eklenti/23, aluminyumrapor.pdf, Yayın tarihi Mayıs 1, 2008. Erişim tarihi Ağustos 2, 2016.

5. Özyürek D., Y1lmaz R., Kibar E., The Effects of Retrogression Parameters in RRA Treatment on Tensile Strength of 7075 Aluminium Alloys, Journal of the Faculty of Engineering and Architecture of Gazi University, 27 (1), 193-203, 2012.

6. Özyürek D., Yılmaz R., Kibar E., The Effects of Retrogression Parameters on Hardness and Wear Behaviours of 7075 Aluminium Alloys, Journal of the Faculty of Engineering and Architecture of Gazi University, 27 (2), 429-438, 2012.
7. Tunçay T., Özyürek D., The Effects on Microstructure and Mechanical Properties Of Filtration in Al-Si-Mg Alloys, Journal of the Faculty of Engineering and Architecture of Gazi University, 29 (2), 271-279, 2014.

8. Zhang L., Ultrasonic Processing of Aluminum Alloys, Master, In Materials Science and Engineering University of Science and Technology, Beijing-China, 2013.

9. Xu H., Jian X., Meek T.T., Han Q., Degassing of Molten Aluminum A356 Alloy Using Ultrasonic Vibration, Mater. Lett., 58, 3669-3673, 2004.

10. Xu H., Meek T.T., Han Q., Effects of ultrasonic field and vacuum on degassing of molten aluminum alloy, Mater. Lett., 61, 1246-1250, 2007.

11. Dadbakhsh S., Hao L., Effect of hot isostatic pressing (HIP) on $\mathrm{Al}$ composite parts made from laser consolidated $\mathrm{Al} / \mathrm{Fe} 2 \mathrm{O} 3$ powder mixtures, J. Mater. Process. Technol., 2474-2483, 2012.

12. Ceschini L., Morri A., Sambogna G., The effect of hot isostatic pressing on the fatigue behaviour of sand-cast A356-T6 and A204-T6 aluminum alloys, J. Mater. Process. Technol., 204, 231-238, 2008.

13. Mostafavi Kashani S.M., Rhodin H., Boutorabi S.M.A., Effects of hot isostatic pressing on the tensile properties of A356 cast alloy, Iranian Journal of Materials Science \& Engineering, 10, 54-64, 2013.

14. Zimmerman F.X., Toops J., Hot Isostatic Pressing: Today and tomorrow, http://www.hasmak.com.tr /eng/tozpdf/HIP-Today-and-Tomorrow.pdf, Yayın tarihi Ocak 15, 2008. Erişim tarihi Ağustos 2, 2016.

15. Lee M.H., Kim J.J., Kim K.H., Kim N.J., Lee S., Lee E.W., Effect of HIPping on high-cycle fatigue properties of investment cast A356 aluminum alloys, Mater. Sci. Eng., A, 340, 123-129, 2003.

16. Ceschini L., Morri A., Sambogna G., The effect of hot isostatic pressing on the fatigue behaviour of sand-cast A356-T6 and A204-T6 aluminum alloys, J. Mater. Process. Technol., 204, 231-238, 2008.

17. Ran G., Zhou J., Wang Q.G., The effect of hot isostatic pressing on the microstructure and tensile properties of an unmodified A356-T6 cast aluminum alloy, J. Alloys Compd., 421, 80-86, 2006.

18. Staley Jr. J.T., Tiryakioğlu M., Campbell J., The effect of increased HIP temperatures on bifilms and tensile properties of A206-T71 aluminum castings, Mater. Sci. Eng., A, 460-461, 324-334, 2007.

19. Dedyaeva E.V., Nikiforov P.N., Padalko A.G., Talanova G.V., Shvorneva L.I., Effect of Barothermal Processing on the Microstructure and Properties of Al10 at \% Si Hypoeutectic Binary Alloy, Inorg. Mater., 52 (7), 721-728, 2016.

20. J.R. Davis, ASTM Specialty Handbook: Aluminum and Aluminum Alloys, 623, 1993.

21. Demir, E., Alüminyum Alaşımlarda Isı1 İşlem Etkierinin İncelenmesi, Dokuz Eylül Üniversitesi Fen Bilimleri Enstitüsü Yüksek Lisans Tezi, 2008. 
